\title{
Rapid Benefit Indicator Tools
}

\author{
Justin Bousquin and Marisa Mazzotta
}

\begin{abstract}
Given the many interconnections between socio-economic and ecological systems, for Ecosystem-Based Management (EBM) to be effective, decision makers must consider metrics for both. Supply side tools and assessments characterize ecosystem condition, functioning, and potential to provide ecosystem goods and services (EGS). Demand side tools, including economic valuation, assess people's preferences for EGS and sometimes estimate the monetary amount people are willing to pay for a good or service. However, economic valuation is often omitted from assessments, due to lack of data or expertise; and economic valuation alone may not sufficiently capture all important aspects of some decisions. Benefit-relevant indicators have evolved as a way to measure the connection between goods or services that may be provided by an ecosystem, and people who may benefit from those services, while stopping short of valuation (Olander et al., Ecol Indic 85:1262-1272, 2018). Like economic valuation, benefit-relevant indicators can help assess trade-offs and compare alternative outcomes (National Ecosystem Services Partnership, Federal resource management and ecosystem services guidebook. National Ecosystem Services Partnership, Duke University, Durham, 2016). The Rapid Benefit Indicators (RBI) approach is an easy-to-use process for choosing a structured set of non-monetary benefit-relevant indicators for assessment (Mazzotta et al., Integr Environ Assess Manag 15:148-159, 2019). The RBI approach indicators are intended to be applied in conjunction with existing ecosystem service assessment approaches and tools, to connect changes in the availability of EGS to the locations where, and how, people benefit from those goods and services. Though developed for use with urban freshwater wetland restoration, the general RBI approach and indicator framework may be adapted and applied to other
\end{abstract}

\footnotetext{
J. Bousquin $(\bowtie)$

US Environmental Protection Agency, Gulf Ecosystem Measurement and Modeling Division, Gulf Breeze, FL, USA

e-mail: Bousquin.Justin@epa.gov

M. Mazzotta

US Environmental Protection Agency, Atlantic Coastal Environmental Sciences Division, Narragansett, RI, USA
} 
environmental changes or ecological systems. This chapter will detail the RBI approach and highlight how RBI tools can inform resource management decisions.

\section{Lessons Learned}

- When implementing EBM, it is not enough to simply maintain or restore the functioning of ecosystems; it is essential to also consider benefits from services that people want and need

- Socio-economic metrics must be linked to changes in ecosystems to be relevant to EBM policy and management questions

- Indicator-based methods inform decisions when direct measures of economic values are unavailable, overly complex, elicit resistance or are otherwise inadequate

- A structured process for selecting benefit indicators, such as the Rapid Benefit Indicators Approach, helps practitioners choose the right metrics

- Tools, such as the RBI checklist tool, the RBI spatial analysis tool and the RBI national catchment dataset, can make it easier for practitioners to evaluate benefits from services as part of their EBM approach

\section{Needs to Advance EBM}

- EBM methods and policy would benefit from more explicitly addressing and communicating benefits to people resulting from managing ecosystems

- EBM practitioners need tools that will allow them to evaluate the services and benefits provided by a wide array of ecosystems

\section{Evaluating Benefits}

Ecologists and economists have embraced the ecosystem services concept as an important support for understanding and managing social-ecological systems. Ecosystem-Based Management (EBM) seeks to protect, maintain or restore ecosystems and their functioning so that they can provide the services that people want and need (Piet et al. 2017; Delacámara et al. 2020). Decisionmakers using an EBM approach need to weigh trade-offs among the benefits and costs of different actions, and ecosystem service metrics can inform those trade-offs. Despite consensus around the importance of considering ecosystem services, it remains difficult for practitioners to choose the right metrics (Boyd et al. 2016; Olander et al. 2017).

There are metrics specific to each component of the ecosystem service framework (Fig. 1). Biophysical metrics are commonly used to model or monitor how an ecological system responds to human actions (the ecological outcomes). Ecosystem service metrics describe the ecosystem goods and services (EGS) produced by the system, based on its condition and resulting ability to perform functions needed to produce those EGS. To avoid double-counting of benefits to people, ecosystem service metrics should measure what is directly enjoyed, consumed or used by people, i.e. final ecosystem goods and services (FEGS; Boyd and Banzhaf 2007; 


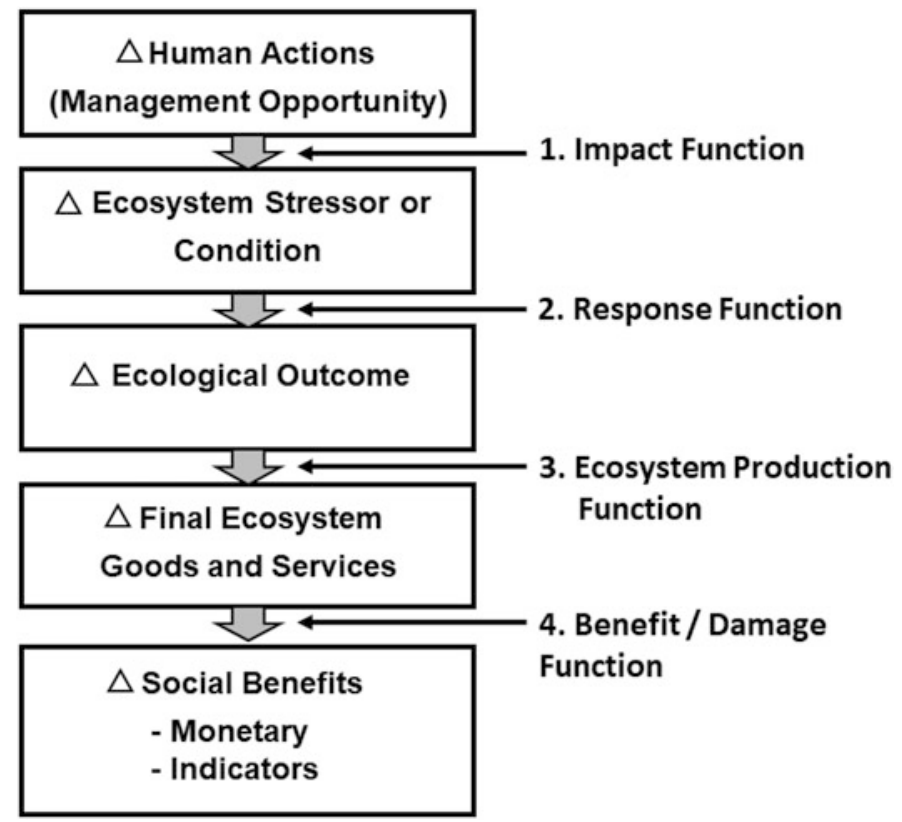

Fig. 1 Conceptual framework linking management actions to ecological change and to socioeconomic benefits. (Adapted from Wainger and Mazzotta 2011)

Ringold et al. 2013). Changes in FEGS that result from human actions will lead to changes in human well-being, which may be measured in monetary terms or using indicators, as presented in this chapter.

There are many tools and metrics available to measure the functioning of ecological systems or their ability to produce ecosystem services, although these do not always measure the endpoints that are most appropriate for evaluating changes in human well-being. For example, there is often a bias towards, or over-reliance on, land use and land cover data (Tashier and Ringold 2019). Simply measuring an ecosystem's ability to produce goods and services does not provide evidence that those goods and services are used or enjoyed by people. Even when using the most precise metrics for ecological outcomes or ecosystem services, if these metrics cannot be linked to the socio-economic benefits that result from changes in the ecosystem, the assessment will be incomplete and risks being irrelevant to people. The closer metrics get to measuring the change in social benefits, the better those metrics can inform trade-offs.

Environmental decision makers, the people deciding between environmental management actions, often require or desire monetary measures of benefits to people. Economic valuation approaches monetize the value of ecosystem goods and services to people (Heal 2000b; Freeman et al. 2014). Valuation methods include the use of market prices, where available (e.g., for commercially-harvested 
EGS such as fish or timber), but most EGS are not traded in markets and thus require the use of non-market valuation methods (National Research Council 2005; Champ et al. 2017). These include revealed preference methods that use people's behavior to infer values (e.g., the travel cost method, Parsons 2017); stated preference methods that use hypothetical questions or comparisons of choices to ask people to directly state their values (e.g. contingent valuation, Bateman and Willis 1999); and benefit transfer methods that apply values from existing studies to a new location and/or context (Johnston et al. 2015). Each of these methods is appropriate for different contexts and types of values. Whereas use values, where people directly interact with FEGS, may be measured by any of these methods; non-use values, where people do not directly interact with the service, can only be measured using stated preference methods or benefit transfer of stated preference studies. Each method has its advantages as well as shortcomings or pitfalls (Champ et al. 2017; Johnston et al. 2015; Freeman et al. 2014). These methods also tend to be resource-intensive, and location- and context-specific (Spash and Vatn 2006; Heal 2000a). Even when valuation studies are performed well, if the estimated values are not appropriately linked to available biophysical models or metrics, or if the appropriate biophysical metrics are not available, the estimated values will not be responsive to changes in ecosystems (Johnston et al. 2012; Schultz et al. 2012). Especially in the context of EBM, socioeconomic metrics that can't be linked to changes in ecosystems are of limited relevance to policy or management questions.

In cases where assessments include metrics linking each component of the ecosystem services framework, decision makers may still face various difficulties in applying a comprehensive EGS assessment. Resource managers who must make decisions affecting EGS, such as state agencies, may not have in-house expertise to conduct an assessment, and may lack resources or support for commissioning an appropriate study. Olander et al. (2017) suggest that many methods are not responsive to policy and management changes, not generalizable enough to transfer from one context to another, or are too burdensome in terms of needed expertise, data or costs. Developing new metrics and assessment tools to fill gaps should involve decision makers to help ensure that their needs are met and that applications are feasible, with relevant outcomes (Ojo et al. 2018). However, tool developers must balance these factors against over-tailoring metrics and tools to be so locationspecific that they are not transferable or overly burdensome to apply. For applied tools to be more widely employed, there often needs to be a shift in emphasis from accuracy to more general applicability and feasibility in terms of time, money, expertise and data availability. Practitioners have limited time and resources to learn new tools and to translate results to be relevant to their stakeholders; often, a less-precise but more easily-applied approach is sufficient for the types of decisions being made, especially when it will be used as part of a broader process of stakeholder engagement and adaptive management (Kline and Mazzotta 2012). 


\section{Non-monetary Benefit Indicators}

Recognizing the limitations of monetary economic valuation, including uncertainties around value estimates but especially with regard to the expertise required and cost of primary studies, indicator-based studies offer an alternative (Boyd and Wainger 2002). Often study results are used primarily to stimulate public discussion or better direct further investigations (Thaler et al. 2014). In these cases, indicators may avoid some of the pitfalls and resistance that value estimates can elicit. Indicators can inform decisions when direct measures of economic value are unavailable, overly complex to estimate, or otherwise inadequate (Meadows 1998; Bossel 1999; Layke 2009). Desirable indicator variables have a strong relationship to the phenomena of interest yet are simple enough to be effectively monitored and/or modeled (Dale and Beyeler 2001).

Benefit indicators, in contrast to strictly biophysical indicators, provide information regarding the benefits and values of ecological changes to people. It is possible to use sound economic principles to formulate these indicators and capture the important aspects of value, while avoiding the burden of calculating dollar values (Mazzotta et al. 2019). Benefit-relevant indicators link biophysical outcomes to benefits for an identifiable group of people, in order to evaluate trade-offs and make decisions. An indicator is considered relevant when it captures something that directly alters beneficiaries' well-being, in units that are relevant to those beneficiaries (Olander et al. 2018).

The National Ecosystem Services Partnership (NESP) Guidebook presents an assessment framework that includes benefit-relevant indicators (NESP 2016). The guidebook suggests that conditions that influence values or preferences fall into five general categories (see also Wainger et al. 2001; Wainger et al. 2010):

1. Service Quality-quality of the service for its intended use

2. Capital and Labor-availability of capital and labor that complement ecological outputs in order to create goods and services

3. Number and characteristics of users

4. Reliability—reliability of the future stream of services

5. Scarcity and Substitutability—number of substitutes for the services provided

By incorporating these five conditions, benefit-relevant indicators complement ecological metrics with indicators more closely tied to what people value and prefer. Methods to measure benefit-relevant indicators can range from simple to complex and such metrics can be qualitative or quantitative. Though benefit-relevant indicators go a long way toward improving metrics, there is a great deal of flexibility and interpretation involved in defining the indicators for application. This level of flexibility makes benefit-relevant indicators broadly applicable; however, it also can result in inconsistency across applications, making them harder to compare or transfer across studies or locations with disparate contexts. While developing and applying benefit-relevant indicators is easier for decision makers than conducting economic valuation, it still requires economic or social science expertise. 


\section{Rapid Benefit Indicators (RBI) Approach}

The Rapid Benefit Indicators (RBI) approach is an easy-to-use screening method for consistent and transparent site level assessment (Mazzotta et al. 2016, Mazzotta et al. 2019). The RBI approach is an extension of previous work on benefit indicators and parallels many benefit-relevant indicator concepts. The RBI approach uses a list of generic questions that capture important aspects of benefits and value to people, similar to the benefit-relevant indicators list of conditions. Practitioners answer each question to develop a set of non-monetary benefit indicators. Using a uniform indicator framework ensures greater consistency, while providing the latitude to select indicators best fitting the decision context. The RBI approach is intended to be used in conjunction with ecosystem service assessment approaches and tools to connect changes in ecosystems to changes in EGS and ultimately to benefits to people.

\subsection{Five Step Rapid Benefit Indicator Process}

The RBI indicators fit within a broader five-step process (Fig. 2) adapted from structured decision-making (Gregory et al. 2012) and in alignment with EBM (DeWitt et al. 2020). Each step in the process builds on the previous step. The first step, describing the decision context, includes identifying stakeholders and their objectives. Based on these objectives, the second step is to select the relevant ecosystem services and resulting benefits to assess, and to specify how those services and benefits are defined. Defining the ecosystem services and benefits is critical in order to be able to select appropriate indicators in step three. Identifying stakeholders, their values and how those values align with ecosystem services and benefits is essential and can be facilitated by FEGS approaches and tools (Sharpe et al. 2020).

Fig. 2 The five-step process used to apply the RBI in decision-making (Mazzotta et al. 2019; adapted from Gregory et al. 2012)

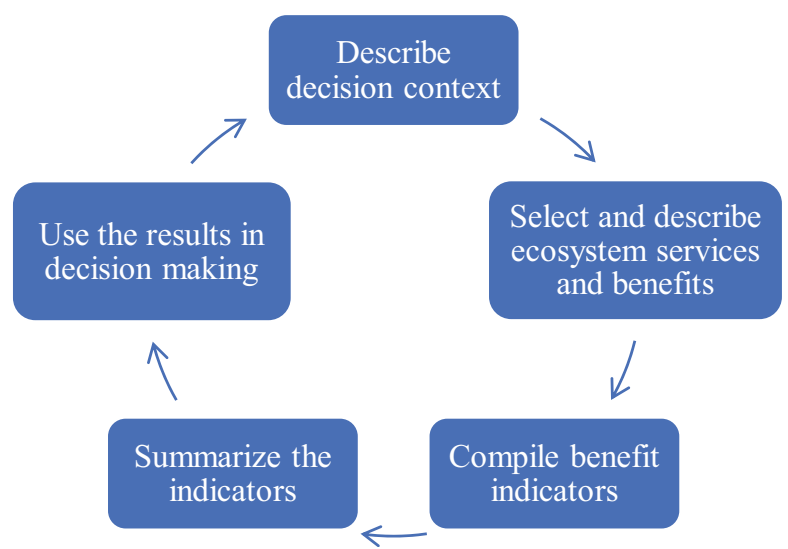


The Rapid Benefit Indicators (RBI) approach Guidebook (Mazzotta et al. 2016) includes a case study where ecosystem services and benefits were selected from a list of those mentioned by resource managers during semi-structured interviews (Druschke and Hychka 2015). This list was further reduced to a set of ecosystem services that result in local benefits that are easily differentiated at a site scale. The RBI approach was designed to be applied at the site scale, which means that EGS that do not vary across sites do not need to be included in the assessment.

In step three, indicators are selected and compiled based on five questions, some with sub-questions. This is described in more detail below. In step four, compiled indicators are summarized to assist interpretation of results. Step five takes results summarized in step four and uses them in decision making.

Fostering adaptive management is a core part of EBM (Delacámara et al. 2020). To support adaptive management, the RBI decision process may be applied iteratively. After indicator results are used in decision making the practitioner may apply the same indicators over time to monitor both the results of actions and how changing conditions in the study area may suggest new priorities for action.

\subsubsection{Rapid Benefit Indicator Questions (Step 3)}

The five questions and their sub-questions are the core of the RBI approach. Some of these questions and sub-questions are optional, while others are required, as discussed further below.

Question 1: Can people benefit from an ecosystem service?

As an initial screening question, this helps determine whether people are able to benefit from an ecosystem service. It requires a site to currently meet, or to meet after restoration, three criteria:

1. It produces a final ecosystem good or service,

2. There are people who will benefit from the EGS, and

3. Complementary inputs required for benefits to reach people, if any, are available.

Sites that do not meet these criteria do not result in a benefit and require no further assessment for that EGS. A site fails the first criterion if it is not large enough or does not have high enough functioning to produce services of the required quantity or quality. For example, a site may be too fragmented to provide habitat for a bird species of interest to bird watchers. A site fails the second criterion if general demand for the service is lacking (see Russell et al. 2020 for similar requirements of Natural Capital Accounting). This is a more superficial precursor to question 2, assessing how many people benefit, and stops short of going into spatial relationships or quantification. For example, nearby flooding after recent storms is strong enough evidence of demand for flood-reduction services, without assessing where flooding occurred in relation to sites. For some ecosystem services, complementary inputs or conditions must be available for enjoyment of the service. A site fails the third criterion if such inputs or conditions are necessary but not available. Examples 
include infrastructure allowing physical access, or lack of institutional constraints such as regulatory harvest limits (NESP 2016; Olander et al. 2018).

Question 2: How many people benefit?

This question focuses on quantifying the pool of people who can benefit from an EGS at each site. In quantifying economic values, often the aggregate value of EGS is more sensitive to the number who benefit than the magnitude of individual values (Bateman et al. 2006). Thus, the number of beneficiaries provides an indication of the total benefits from an ecological change. The RBI uses a spatial approach to count beneficiaries, defining how services flow to people, defining the area where people may benefit, and quantifying the number of people who could benefit within the defined area. Services are generally produced in-situ and then either services flow to areas where people can access them, people travel to the site to access services, or both. RBI uses three general categories (Fig. 3) to characterize these spatial relationships (Fisher et al. 2009; Bagstad et al. 2013):

(a) Services are generated and must be enjoyed on site or within a geographic area (Fig. 3a), for example, through recreational uses of a site. To benefit, people must be located at or travel to that site or geographic area. When evaluating these services, the pool of beneficiaries depends on how far people will travel to the site.

(b) Services are generated on site and flow in all directions to a surrounding area (Fig. 3b), for example, birds or pollinators that use the site for habitat and move through nearby areas where people can benefit. People within the area where services flow will be able to benefit. When evaluating these services, it is important to consider how far services travel, whether those travel paths are blocked in any direction, and how those travel paths overlap with people who might benefit.

(c) Services are generated on site and flow in a single, or restricted, direction to a surrounding area (Fig. 3c), for example, downstream flood risk reduction from a wetland. People within the area where services flow will be able to benefit. This is true for services that flow downstream, such as water retention or purification. When evaluating these services, it is important to consider how far services

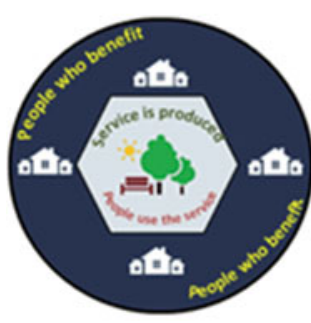

a

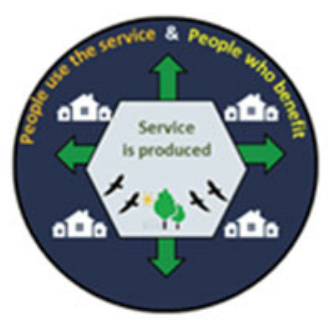

b

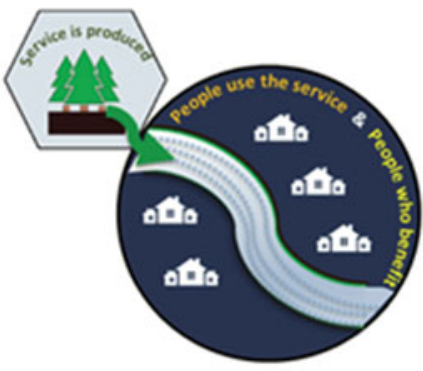

C

Fig. 3 The three categories RBI uses to characterize spatial relationships between where services are produced and where people access them (Mazzotta et al. 2019) 
travel, whether anything impedes or assists that flow, in what direction, and how the travel path overlaps with people who might benefit.

Nonuse values for EGS that are important to people although they do not directly interact with them are a special case in which people do not have to be in any particular spatial relationship to the service, but simply need to be aware of the service and value it. These services can benefit people at varying distances without direct contact with people. For example, people may value the fact that a site provides habitat for a rare or unique species, although they do not see or interact with that species. The RBI approach is not tailored to the complexities of evaluating nonuse services, which are beyond the scope of this method. However, if a site is particularly rare or unique, or contains rare species, nonuse values may be significant and should be noted and evaluated using other approaches (Wainger et al. 2018; Richardson and Loomis 2009).

The spatial extent of relevant areas for assessment will vary based on local conditions and attributes of the ecosystem, landscape, and beneficiaries (Vajjhala et al. 2008). Distance decay may impact the service, causing service quantity or quality to decrease with distance from the source (Fisher et al. 2009; Bagstad et al. 2013). Services may also decrease in quantity or quality when they encounter "sinks," features on the landscape that absorb, degrade or deplete the service or the conduit transporting the service (Bagstad et al. 2013). Like services, benefits may experience distance decay, where people's values diminish with increasing distance from the area where services are accessed (Hanley et al. 2003; Bateman et al. 2006; Campbell et al. 2007; Campbell et al. 2008). One way to account for decreasing benefits with distance is to divide the number of beneficiaries into beneficiary pools based on distance bands and assigning lower weight to farther bands to help account for the decay in value. For example, when evaluating a recreational service, the number of beneficiaries within walking distance and driving distance may be estimated separately, with lower weight applied to those farther away.

Question 3: How much are people likely to benefit?

This question assesses the magnitude of benefits. How much people benefit from an ecosystem service is assessed by indicators answering four questions. Some of these questions may not be relevant to every ecosystem service, and those that are relevant may have one or more indicators. These questions are based on core concepts of economic theory of supply, demand, and value (Freeman et al. 2014; Nicholson and Snyder 2012). Economic theory posits that each of these factors, all else equal, will increase or decrease a person's value for a good or service through their effects on the demand function (the function that relates price or willingness to pay to quantity and quality of a good or service).

a. What is the quality of the service?

People benefit more from higher quality ecosystem services. Existing tools that measure the functioning of ecological systems or their ability to produce ecosystem services (e.g. Lewis et al. 2020; Culhane et al. 2020) may help inform assessment of the quality of ecosystem services provided by a site. 


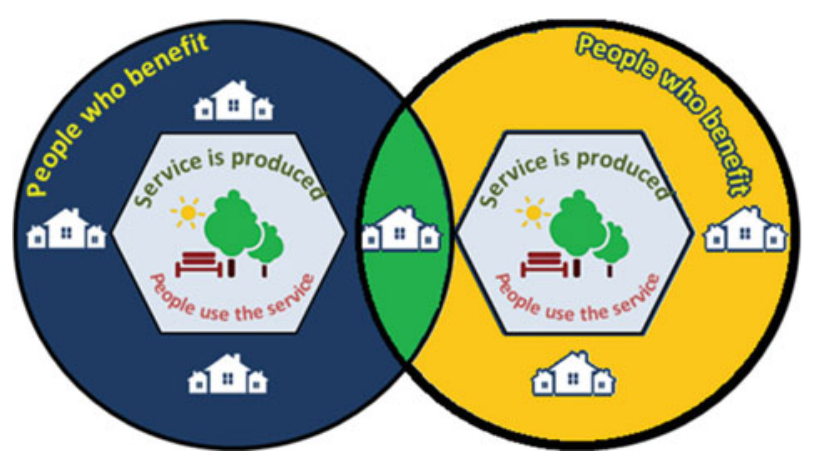

Fig. 4 In this illustration, the service areas shown in the blue and yellow circles represent recreational parks, and the location of individual beneficiaries is indicated by the house icons in each circle. The house within the green overlap area has access to two parks, where other homes depicted each can easily access only one park. Therefore, services provided by the parks are less scarce for the house in the green area and an additional park will have a lower incremental value for people in that location, than for those living in the other homes depicted, who have fewer substitutes (Yee et al. 2017)

\section{b. Are there substitutes for the service or is the service scarce?}

In general, people benefit less from each additional unit of a good or service they could receive. In other words, for a given beneficiary, the more units of a service that are available, the lower the value of more of that service or additional sources of that service (Yee et al. 2017; Fig. 4). Thus, fewer substitutes or greater scarcity lead to higher value, all else equal. The scarcity of ecosystem services already available to beneficiaries is informed by estimating the number of similar ecosystems and/or technological substitutes already providing those services. An increase in substitutes indicates lower value, so the direction of influence is reversed for this indicator as compared to the others.

\section{c. What is the quality of complements to the EGS?}

For some EGS, complements may be required for people to benefit, or may enhance benefits. For example, without a boat launch, people may not be able to access a waterway to benefit from recreational boating; and a higher quality boat launch will enhance benefits of boating. Thus, people benefit more when the quality of complementary inputs, other goods and services used with the ecosystem service, is higher. This is only important for services that are enhanced by complementary factors.

\section{d. How strong are people's preferences?}

People's strength of preferences influences their economic value (willingness to pay) for improvements in a good or service. In general, those with stronger preferences will benefit more from a given improvement in a good or service. For example, a more avid birder may have a higher value for improved bird habitat and resultant birding opportunities than someone who is less interested in birding. Characteristics of the beneficiaries that influence preferences are specific to the local context and the 
EGS in question and may involve complex interactions among factors, and thus may be difficult to account for. In practice, this factor may often be omitted from assessment due to lack of data, or may be incorporated through more qualitative approaches such as opportunities for public comment.

Question 4: What are the social equity implications?

Determining social equity implications examines the population receiving the benefits and evaluates whether they are socio-economically disadvantaged. Benefits can be more important for vulnerable populations or people facing environmental concerns. These groups tend to have fewer resources to access ecosystem services yet may rely on them more (Norman et al. 2012). Similar to quantification of how many people benefit (Question 2), evaluating social equity implications involves characterizing the spatial relationship between where services are produced and where people access them. However, instead of quantifying the number of people who benefit, what is important for social equity is characterizing attributes of the people who benefit that make that population socio-economically disadvantaged.

Question 5: How reliable are benefits expected to be over time?

Determining the reliability of benefits over time explores the probability that some change will occur over time to inhibit the production of services or flow of benefits to people. When benefits are provided reliably over a longer period the total value of those benefits is greater. For example, benefits of a restored coastal marsh will diminish over time if the marsh becomes submerged due to sea-level rise. Features that impact the reliable delivery of services over time need to be sitespecific but not necessarily benefit-specific.

\subsubsection{Using Answers to Rapid Benefit Indicator Questions in Decision Making (Steps 4 \& 5)}

After developing a set of indicators and quantifying those indicators by answering the five generic questions, the next step, step four, is to summarize the indicator metrics. Summarizing metrics into a table can help when making comparisons across sites. These summary tables are analogous to the consequence tables used in structured decision making (see Gregory et al. 2012 for examples), where metrics evaluate the performance of each site. All tools developed to facilitate application of the RBI approach (described below) provide a summary table for this step. This summary table does not rank sites quantitatively or aggregate metrics.

The last step in the process, step five, is to evaluate the metrics in the summary table in light of the decision(s) to be made. There are many ways to weigh the different metrics and the resulting trade-offs when choosing among different actions for different sites. The indicator metrics may be used as is in disaggregated form as a basis for discussions, to inform participatory or consensus-type decisions; or they may be aggregated using Multi-Criteria Decision Analysis (MCDA) methods (Belton and Stewart 2002; Gregory et al. 2012). MCDA methods have successfully been used to aggregate RBI metrics (Martin and Mazzotta 2018a, b; Martin et al. 2018). 


\section{Tools for Applying the Rapid Benefit Indicator Approach}

The RBI approach was originally developed for application to urban freshwater wetland restoration. The general approach and indicator framework will work with other types of environmental changes or within different ecological systems. Indicators for five benefits of urban freshwater wetlands (Fig. 5) have been previously developed and integrated into tools that help users more easily apply the Rapid Benefit Indicators approach.

The rest of this chapter focuses on three tools developed to assist in applying the RBI approach:

\section{Checklist Tool}

2. Spatial Analysis Toolset

3. National Catchment Dataset

These tools are available for download for those practitioners who may want to use them in their application, or use them as models that may be modified for other services and contexts. Each tool has unique aspects that make it more or less useful to specific audiences and applications (Table 1). For example, two of the tools produce a color-coded summary report for indicator results (Fig. 6).

\begin{tabular}{|ll|} 
Ecosystem Service & How people benefit \\
Flood water regulation & $\begin{array}{l}\text { Reduced Flood Risk: The risks from } \\
\text { floods to people and structures are } \\
\text { reduced. }\end{array}$ \\
\hline Scenic landscapes & $\begin{array}{l}\text { Scenic Views: People can enjoy } \\
\text { scenic views. }\end{array}$ \\
\hline Recreational opportunities & $\begin{array}{l}\text { Environmental Education: People } \\
\text { can benefit from studying nature or } \\
\text { from enhanced connection to nature. } \\
\text { recreation }\end{array}$ \\
\hline
\end{tabular}

Fig. 5 The five ecosystem services and benefits that have previously developed indicators for freshwater wetlands restoration sites (Mazzotta et al. 2019) 
Table 1 Differences between tools

\begin{tabular}{l|l|l|l|l|l}
\hline Tool name & $\begin{array}{l}\text { Software } \\
\text { required }\end{array}$ & $\begin{array}{l}\text { Custom } \\
\text { benefits }\end{array}$ & $\begin{array}{l}\text { Summary } \\
\text { report }\end{array}$ & Guidance & $\begin{array}{l}\text { Main } \\
\text { advantage }\end{array}$ \\
\hline Checklist tool & Excel/PDF & Y & Y & High & $\begin{array}{l}\text { Document } \\
\text { process }\end{array}$ \\
\hline $\begin{array}{l}\text { Spatial analysis } \\
\text { toolset }\end{array}$ & ArcGIS & Limited & Y & Medium & Automated \\
\hline $\begin{array}{l}\text { National Catchment } \\
\text { Dataset }\end{array}$ & GIS & N & N & Low & $\begin{array}{l}\text { No data } \\
\text { required }\end{array}$ \\
\hline
\end{tabular}
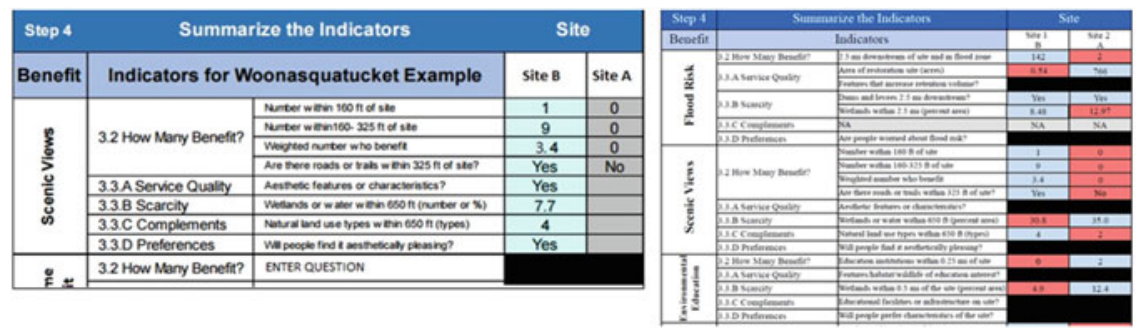

Fig. 6 Partial example color-coded summary reports produced by the Checklist Tool (Left) and Spatial Analysis Toolset (Right)

\subsection{RBI Checklist Tool}

The Rapid Benefit Indicators (RBI) checklist tool ${ }^{1}$ is for recording results of manually-conducted analysis. Users can develop indicators using a variety of resources including paper maps, online maps, stakeholder engagement, or site visits. The checklist tool helps users go through the assessment process and provides space to document data sources, assumptions and other supplemental information.

The checklist tool is available in a pdf format as a low-tech solution that users can fill out by hand and print. The first two pages document the decision context and scope the ecosystem services and benefits being assessed. The next five pages of the pdf are each specific to one of the five ecosystem services and benefits that have previously developed indicators (Fig. 5). The last page is for summarizing results. In some cases, data entered in earlier pages of the pdf are automatically copied to their section in the summary table.

The macro-enabled Excel checklist tool has added functionality that walks the tool user through the step by step decision process. The Excel checklist tool uses responses entered in each form to dictate the next entry. For example, if a site fails to

\footnotetext{
${ }^{1}$ https://cfpub.epa.gov/si/si_public_record_Report.cfm?Lab=NHEERL\&dirEntryId=331110.
} 
meet criteria in Question 1, the tool skips forms for Questions 2-5 for that site. The Excel checklist has built-in forms for the five ecosystem services and benefits with previously developed indicators (Fig. 5). The Excel checklist can also document and assess newly developed indicators for different benefits, new ecological systems or different ecological changes using the five-question framework from the RBI approach. When site assessment is complete, the Excel checklist tool automatically summarizes indicators in a color-coded summary table (Fig. 6), where red indicates worse, blue indicates better, and gray indicates NA/neutral, relative to the average for all sites (for quantitative indicators) or based on characteristics increasing or decreasing benefits (for yes/no indicators). This summary does not rank sites.

\subsection{RBI Spatial Analysis Tools}

The Rapid Benefit Indicators (RBI) spatial analysis tools ${ }^{2}$ compile indicators based on spatial data (Bousquin et al. 2017). Where datasets are available, this significantly expedites analysis. However, spatially-derived indicators are not adequate for answering all of the questions in the RBI approach. This tool is specific to the five ecosystem services and benefits with previously developed indicators (Fig. 5). This tool requires some familiarity with Geographic Information Systems (GIS). Results are summarized by site in table format, either spatially in the site dataset attribute table or as a pdf report (Fig. 6). Although the results are summarized spatially, the tool does not symbolize the results on a map or produce map products directly.

The Rapid Benefit Indicators (RBI) spatial analysis tools are an ArcGIS Python toolbox. This means users must have ESRI's desktop software, ArcMap ${ }^{\circledR}$ or ArcCatalog $\AA$, to open and use the tools (ESRI 2011). The toolbox does not require installation; users simply point ArcMap or ArcCatalog to it and then interact with it just like other toolboxes. Being written as a Python toolbox makes the tools more transparent and adaptable. Users who are familiar with the Python language can open the code and see all input handling and processes. This makes it easier to update inputs or processing to fit newly developed indicators.

The spatial analysis toolset includes seven individual tools (Table 2). The main tool, the Full Indicator Assessment Tool, runs a complete analysis of any or all of the five existing ecosystem services and their benefits. This is the fastest way to assess multiple ecosystem services and benefits. The additional tools in the toolset perform partial analysis. Part tools perform a variety of functions, including downloading data (e.g. Flood Data Download Tool), performing partial analysis using user updated parameters (e.g. Social Equity of Benefits Tool where the default buffer distance can be altered), or performing a specific part of the analysis that could be transferable to newly developed indicators (e.g. the Presence/Absence to Yes/No Tool can test for the presence of other spatial features near a site that could serve as indicators).

\footnotetext{
${ }^{2}$ https://cfpub.epa.gov/si/si_public_record_Report.cfm?Lab=NHEERL\&dirEntryId=338471.
} 
Table 2 Individual tools in the spatial analysis toolset

\begin{tabular}{l|l}
\hline Tool name & Purpose \\
\hline Full indicator assessment tool & Assess any/all of five benefit indicators \\
\hline Benefit reliability tool & Assess benefit reliability (Question 5) \\
\hline Flood data download tool & Download hydrologic data for flood risk indicators \\
\hline Flood risk reduction tool & Assess reduced flood risk benefit indicators \\
\hline Presence/absence to yes/no tool & Assess presence/absence for custom benefit indicators \\
\hline Report generation tool & Summarize indicator results \\
\hline Social equity of benefits tool & Assess benefit social equity implications (Question 4) \\
\hline
\end{tabular}

Table 3 National spatial datasets to use as default inputs

\begin{tabular}{|c|c|c|}
\hline Data layer name & Source & Description \\
\hline $\begin{array}{l}\text { Restoration site } \\
\text { polygons }\end{array}$ & EnviroAtlas $^{\mathrm{a}}$ & $\begin{array}{l}\text { Potentially restorable wetlands on agricultural } \\
\text { land }\end{array}$ \\
\hline Population raster & EnviroAtlas $^{1}$ & Dasymetric population \\
\hline Address points & OpenStreetMap & OSM buildings ${ }^{\mathrm{b}}$ \\
\hline Flood zone polygons & $\begin{array}{l}\text { FEMA, } \\
\text { EnviroAtlas }^{1}\end{array}$ & $\begin{array}{l}\text { Flood zones } \\
\text { Estimated Flood Plains }\end{array}$ \\
\hline Dams/levees & USGS & National Hydrography Dataset \\
\hline Wetland polygons & EnviroAtlas $^{1}$ & National Wetlands Inventory \\
\hline Catchments & NHDPlusV2 ${ }^{\mathrm{d}}$ & Catchments \\
\hline Conservation lands & EnviroAtlas $^{1}$ & Protected Areas Database of the US (PADUS) \\
\hline $\begin{array}{l}\text { Landuse/Greenspace } \\
\text { polygons }\end{array}$ & $\begin{array}{l}\operatorname{NLCD}^{\mathrm{e}} \\
\text { NOAA }^{\mathrm{f}}\end{array}$ & $\begin{array}{l}\text { National Land Cover Database (NLCD) } \\
\text { Coastal change analysis program (C-CAP) }\end{array}$ \\
\hline Trails & OpenStreetMap ${ }^{g}$ & HikeBikeMap \\
\hline Roads & $\begin{array}{l}\text { TIGER/line, } \\
\text { OpenStreetMap }^{7}\end{array}$ & $\begin{array}{l}\text { Roads } \\
\text { Roads }\end{array}$ \\
\hline $\begin{array}{l}\text { Educational institu- } \\
\text { tion points }\end{array}$ & $\mathrm{DHS}^{\mathrm{i}}$ & $\begin{array}{l}\text { Homeland infrastructure foundation-Public } \\
\text { schools, private schools }\end{array}$ \\
\hline Bus stops & OpenStreetMap $^{7}$ & Buses \\
\hline Social vulnerability & $\begin{array}{l}\text { SVI, } \\
\text { EJScreen }^{\mathrm{j}}\end{array}$ & $\begin{array}{l}\text { Social vulnerability index } \\
\text { Demographic indicators }\end{array}$ \\
\hline
\end{tabular}

ahttps://enviroatlas.epa.gov/enviroatlas/interactivemap/

b https://osmbuildings.org/

chttps://msc.fema.gov/portal/search

${ }^{\mathrm{d}}$ http://www.horizon-systems.com/NHDPlus/NHDPlusV2_data.php

ehttps://www.mrlc.gov/data

${ }_{\mathrm{f}} \mathrm{https}$ ///coast.noaa.gov/digitalcoast/data/ccapregional.html

$\mathrm{g}_{\text {https://www.openstreetmap.org }}$

${ }^{h}$ https://www.census.gov/geo/maps-data/data/tiger-line.html

i https://hifld-geoplatform.opendata.arcgis.com/

${ }^{\mathrm{j}}$ https://coast.noaa.gov/digitalcoast/data/sovi.html

${ }^{k}$ https://ejscreen.epa.gov/mapper/

Although the way spatial analysis tools analyze data is predefined, there is flexibility in what the user can load as input datasets. Most of the inputs have nationally consistent datasets that can serve as a default (Table 3). This helps ensure the tools will not require data collection in most places. In many cases there are better 
alternatives to the national data. For example, national datasets may be incomplete (e.g. FEMA Flood zones; Bousquin and Hychka 2019), may lead to less precise results (e.g. EnviroAtlas raster population data when compared to address points; Bousquin et al. 2015), or may have higher resolution local datasets (e.g. statewide land use datasets like the one used in the Woonasquatucket watershed, RI case study; Martin et al. 2018).

\subsection{RBI National Catchment Dataset}

The Rapid Benefit Indicators (RBI) catchment dataset ${ }^{3}$ allows a user to compare sites in different catchments based on a catchment characterization previously performed using a sub-set of indicator metrics (Bousquin and Hychka 2019). Rather than being a tool to help users analyze their data, this is a national dataset of results for two indicators of reduced flood risk benefits. The first indicator answers question two, how many people benefit. The second indicator answers the $i$ s the service scarce part of question three, how much are people likely to benefit. Using this dataset provides the least flexibility, as indicators and data inputs are predetermined.

Using this dataset requires some GIS experience, as comparing the data across restoration sites requires several steps. First, users can download these results as a comma separated values (csv) file for their region of interest. Next users will need to download the NHDPlusV2 catchment shapefile for their region. This catchment shapefile is the same one the spatial analysis tools use (Table 3). The csv file contains a "COMID" field to join the data to the NHDPlusV2 catchment shapefile's "FEATUREID" field. After joining the csv to the shapefile, GIS software (e.g. ArcGIS, QGIS, grass, R, etc.) can be used to visualize data by catchment. Catchment results can then be overlaid and compared to locations for restoration sites (Fig. 7). Comparisons can be visual, using site coordinates or imagery, or spatial, overlaying and summarizing indicators for a shapefile of sites.

Each catchment has 15 columns or fields. Most fields represent similar information but aggregated in different ways or determined based on different data. Each row presents values for a specific catchment. The dataset does not have the spatial resolution to differentiate sites within the same catchment.

For the first indicator, how many people benefit, beneficiaries are people in floodprone areas downstream of a wetland restoration (Fig. 7). If restored, these people are in proximity to receive reduced flood-risk as a result. We recommend using values in either the "EA_pct_d" or "fld_pct_d" fields. These values represent the sum of the population in flood-prone areas in that catchment and catchments five $\mathrm{km}$ downstream. The difference between the two fields is in the data used to identify flood-prone areas. In the "EA_pct_d" field, an EnviroAtlas modeled layer defines flood-prone areas (Woznicki et al. 2019). In the "fld_pct_d" field, FEMA inland flood zones define flood-prone areas (FEMA 2018). Both estimates overlay the

${ }^{3}$ https://catalog.data.gov/dataset/nhdplusv2-catchment-rbi-data. 


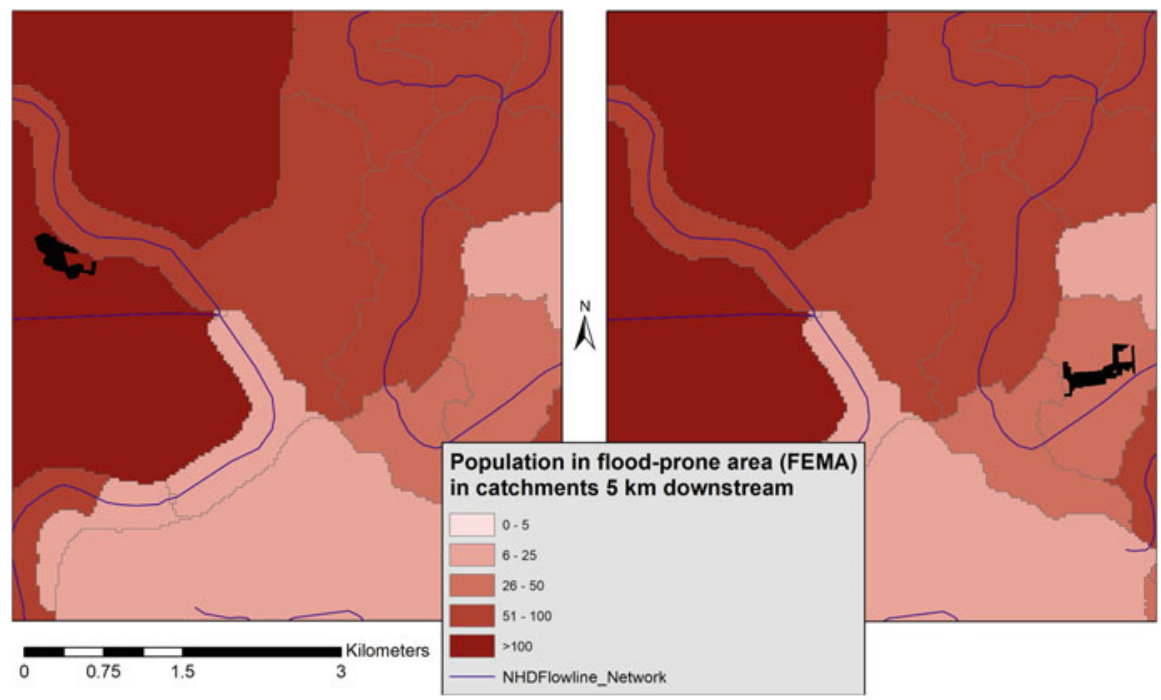

Fig. 7 Once catchments results from the csv file are joined to a spatial catchments dataset sites can be overlaid and compared based on characterizations for the catchment they fall within. This example shows a site (black) in a catchment with $>100$ people in FEMA flood-prone areas downstream of the site (Left) compared to a nearby site (black) in a catchment with 33 people in FEMA flood-prone areas downstream of the site (Right)

flood-prone areas with the same dasymetric 2010 population data and use the same methods to combine estimates from downstream catchments. Where there are more people in flood-prone areas downstream there is more demand for increased floodreduction benefits. Thus, it is a maximizing criterion, and a higher value makes a catchment higher priority for restoration.

For the second indicator, is the service scarce, existing wetlands may already be providing flood-risk reduction services for the same beneficiaries. We recommend using values in the field "wet_pct", which represent the percent of that catchment that is currently wetlands. In catchments with abundant wetlands already providing flood-reduction services, added units of this service have less value than in catchments where wetlands providing flood-reduction services are scarce. Thus, it is a minimizing criterion, and a lower value makes a catchment higher priority for restoration.

The two indicator field values may need manipulation to inform decision making. Regions have physiographic differences that impact wetland suitability, flood-risk, and population density. As a result, the distribution of values within different regions is diverse. For example, a $10 \%$ difference in wetlands between catchments in west Texas is drastic but would be minor in coastal Minnesota. To account for this, Bousquin and Hychka (2019) suggest binning the indicators into discrete categories based on the distribution of regional values, and show a method using four quartiles, dividing catchment values into four categories of equal number. Different discretizations are better suited depending on thresholds, decision context and overarching objectives. Many GIS applications aid users in choosing discrete categories when visualizing data. 


\section{Summary}

The RBI approach helps formalize a process for developing benefit indicators for site-level assessment. The RBI approach is a rapid screening assessment, meant to reduce the burden in expertise, data, and cost placed on practitioners using socioeconomic metrics. The three tools described here were developed to help decisionmakers apply the RBI approach indicators in a consistent and transparent way. These tools were developed for a subset of EGS and applied within the context of urban freshwater wetlands and could be modified or reproduced for other ecosystems and services. In a case-study application of the spatial analysis tool, we screened 65 candidate restoration sites within a watershed, using the RBI combined with MCDA methods, and identified four preferred restoration sites. These sites were further considered by a local watershed group, which subsequently proposed three of the sites for restoration, based on the sites' potential EGS values to local beneficiaries (Martin et al. 2018).

Each of the RBI tools addresses different user needs. The checklist tool is for recording results of manually-conducted assessments or for developing new indicators for other types of environmental changes or within different ecological systems. The spatial analysis tool is for users with some GIS expertise who have geospatial data to apply the existing rapid benefit indicators for urban freshwater wetland restoration sites. The NHDPlus national catchment dataset is for users only interested in assessing flood-protection benefits. Users of this dataset must be willing to accept reduced flexibility in exchange for not having to perform analysis on multiple input data sets.

We have presented a framework for consistently developing a set of benefit indicators, along with a set of tools for applying this framework. Alongside ecosystem service metrics, benefit indicators help ecological and social interactions be better considered within an Ecosystem-Based Management framework. When stakeholder values are used to select ecosystem services to assess and are reflected in benefits assessments selection trade-offs are better informed and social-ecological systems are better connected in Ecosystem-Based management decision-making.

Disclaimer This chapter has been subjected to Agency review and has been approved for publication. The views expressed in this paper are those of the author(s) and do not necessarily reflect the views or policies of the U.S. Environmental Protection Agency. 


\section{References}

Bagstad, K., Johnson, G., Voigt, B., \& Villa, F. (2013). Spatial dynamics of ecosystem service flows: A comprehensive approach to quantifying actual services. Ecosystem Services, 4, 117-125. https://doi.org/10.1016/j.ecoser.2012.07.012.

Bateman, I., \& Willis, K. (1999). Valuing environmental preferences: Theory and practice of contingent valuation method. Oxford: Oxford University Press on Demand.

Bateman, I., Day, B., Georgiou, S., \& Lake, I. (2006). The aggregation of environmental benefit values: Welfare measures, distance decay and total WTP. Ecological Economics, 60, 450-460. https://doi.org/10.1016/j.ecolecon.2006.04.003.

Belton, V., \& Stewart, T. (2002). Multiple criteria decision analysis: An integrated approach (372 p). Boston, MA: Kluwer Academic Publishers.

Bossel, H. (1999). Indicators for sustainable development: Theory, methods, applications. A report to the Balaton group (123 p). Winnipeg, MB: International Institute for Sustainable Development.

Bousquin, J., \& Hychka, K. (2019). A geospatial assessment of flood vulnerability reduction by freshwater wetlands - a benefit indicators approach. Frontiers in Environmental Sciences, 54, $1-14$.

Bousquin, J., Hychka, K., \& Mazzotta, M. (2015). Benefit indicators for flood regulation services of wetlands: A modeling approach. Narragansett, RI: US Environmental Protection Agency, Office of Research and Development, National Health and Environmental Effects Research Laboratory, Atlantic Ecology Division. EPA/600/R-15/191.

Bousquin, J., Mazzotta, M., \& Berry, W. (2017). Rapid benefit indicator (RBI) spatial analysis toolset and manual. Gulf Breeze, FL: US EPA Office of Research and Development, National Health and Environmental Effects Research Laboratory, Gulf Ecology Division. https://www. epa.gov/water-research/rapid-benefit-indicators-rbi-approach.

Boyd, J., \& Banzhaf, S. (2007). What are ecosystem services? The need for standardized environmental accounting units. Ecological Economics, 63(2-3), 616-626. https://doi.org/10.1016/j. ecolecon.2007.01.002.

Boyd, J., \& Wainger, L. (2002). Landscape indicators of ecosystem service benefits. American Journal of Agricultural Economics, 84(5), 1371-1378.

Boyd, J., Ringold, P., Krupnick, A., Johnson, R., Weber, M., \& Hall, K. (2016). Ecosystem services indicators: Improving the linkage between biophysical and economic analyses. International Review of Environment and Resource Economics, 8, 359-443. https://doi.org/10.2139/ssrn. 2662053.

Campbell, D., Hutchinson, W., \& Scarpa, R. (2007). Using choice experiments to explore the spatial distribution of willingness to pay for rural landscape improvements. Environmental Planning A, 41(1), 97-111. https://doi.org/10.1068/a4038.

Campbell, D., Scarpa, R., \& Hutchinson, W. (2008). Assessing the spatial dependence of welfare estimates obtained from discrete choice experiments. Letters in Spatial Resource Sciences, 1, 117-126. https://doi.org/10.1007/s12076-008-0012-6.

Champ, P. A., Boyle, K. J., \& Brown, T. C. (Eds.). (2017). A primer on nonmarket valuation (2nd ed.). Dordrecht: Springer.

Culhane, F. E., Robinson, L. A., \& Lilleb $\varnothing$, A. I. (2020). Approaches for estimating the supply of ecosystem services: Concepts for ecosystem-based management in coastal and marine environments. In T. O'Higgins, M. Lago, \& T. H. DeWitt (Eds.) Ecosystem-based management, ecosystem services and aquatic biodiversity: Theory, tools and applications (pp. 105-126). Amsterdam: Springer.

Dale, V., \& Beyeler, S. (2001). Challenges in the development and use of ecological indicators. Ecological Indicators, 1, 3-10. https://doi.org/10.1016/S1470-160X(01)00003-6.

Delacámara, G., O'Higgins, T., Lago, M., \& Langhans, S. (2020). Ecosystem-based management: moving from concept to practice. In T. O'Higgins, M. Lago, \& T. H. DeWitt (Eds.), Ecosystem- 
based management, ecosystem services and aquatic biodiversity: Theory, tools and applications (pp. 39-60). Amsterdam: Springer.

DeWitt, T. H., Berry, W. J., Canfield, T. J., Fulford, R. S., Harwell, M. C., Hoffman, J. C., Johnston, J. M., Newcomer-Johnson, T. A., Ringold, P. L., Russel, M. J., Sharpe, L. A., \& Yee, S. J. H. (2020). The final ecosystem goods and services (FEGS) approach: A beneficiarycentric method to support ecosystem-based management. In T. O’Higgins, M. Lago, \& T. H. DeWitt (Eds.), Ecosystem-based management, ecosystem services and aquatic biodiversity: Theory, tools and applications (pp. 127-148). Amsterdam: Springer.

Druschke, C. G., \& Hychka, K. C. (2015). Manager perspectives on communication and public engagement in ecological restoration project success. Ecology and Society, 20(1), 58.

ESRI. (2011). ArcGIS Desktop: Release 10. Redlands, CA: Environmental Systems Research Institute.

FEMA. (2018). FEMA flood map service center portal. Website and web map. Retrieved from https://msc.fema.gov/portal/search.

Fisher, B., Turner, R., \& Morling, P. (2009). Defining and classifying ecosystem services for decision making. Ecological Economics, 68(3), 643-653. https://doi.org/10.1016/j.ecolecon. 2008.09.014.

Freeman, A., Herriges, J., \& Kling, C. (2014). The measurement of environmental and resource values: Theory and methods (3rd ed.). New York: RFF Press.

Gregory, R., Failing, L., Harstone, M., Long, G., McDaniels, T., \& Ohlson, D. (2012). Structured decision making: A practical guide to environmental management choices (312 p). Chichester, UK: Wiley-Blackwell.

Hanley, N., Schläpfer, F., \& Spurgeon, J. (2003). Aggregating the benefits of environmental improvements: Distance-decay functions for use and non-use values. Journal of Environmental Management, 68, 297-304. https://doi.org/10.1016/S0301-4797(03)00084-7.

Heal, G. (2000a). Valuing ecosystem services. Ecosystems, 3(1), 24-30. https://doi.org/10.1007/ s100210000006.

Heal, G. (2000b). Nature and the marketplace: Capturing the value of ecosystem services. Washington, DC: Island Press.

Johnston, R., Schultz, E., Segerson, K., Besedin, E., \& Ramachandran, M. (2012). Enhancing the content validity of stated preference valuation: The structure and function of ecological indicators. Land Economics, 88(1), 102-120. https://doi.org/10.3368/Ie.88.1.102.

Johnston, R., Rolfe, J., Rosenberger, R., \& Brouwer, R. (2015). Benefit transfer of environmental and resource values (Vol. 14). New York: Springer.

Kline, J., \& Mazzotta, M. (2012). Evaluating tradeoffs among ecosystem services in the management of public lands. Gen. Tech. Rep. PNW-GTR-865. Portland, OR: US Department of Agriculture, Forest Service, Pacific Northwest Research Station. 48 p, 865.

Layke, C. (2009). Measuring nature's benefits: A preliminary roadmap for improving ecosystem service indicators (36 p). Washington, DC: World Resources Institute.

Lewis, N. S., Marois, D. E., Littles, C. J., \& Fulford, R. S. (2020). Projecting changes to coastal and estuarine ecosystem goods and services- models and tools. In T. O'Higgins, M. Lago, \& T. H. DeWitt (Eds.). Ecosystem-based management, ecosystem services and aquatic biodiversity: Theory, tools and applications (pp. 235-254). Amsterdam: Springer.

Martin, D., \& Mazzotta, M. (2018a). Non-monetary valuation using multi-criteria decision analysis: Sensitivity of additive aggregation methods to scaling and compensation assumptions. Ecosystem Services, 29, 13-22. https://doi.org/10.1016/j.ecoser.2017.10.022.

Martin, D. M., \& Mazzotta, M. (2018b). Non-monetary valuation using multi-criteria decision analysis: Using a strength-of-evidence approach to inform choices among alternatives. Ecosystem Services, 33, 124-133. https://doi.org/10.1016/j.ecoser.2018.06.001.

Martin, D., Mazzotta, M., \& Bousquin, J. (2018). Combining ecosystem services assessment with structured decision making to support ecological restoration planning. Environ Manag, 62(3), 608-618. https://doi.org/10.1007/s00267-018-1038-1. 
Mazzotta, M., Bousquin, J., Ojo, C., Hychka, K., Gottschalk Druschke, C., Berry, W., \& McKinney, R. (2016). Assessing the benefits of wetland restoration: A rapid benefit indicators approach for decision makers. Narragansett, RI: USEPA, Office of Research and Development. EPA/600/R-16/084.

Mazzotta, M., Bousquin, J., Berry, W., Ojo, C., McKinney, R., Hyckha, K., \& Druschke, C. G. (2019). Evaluating the ecosystem services and benefits of wetland restoration by use of the rapid benefit indicators approach. Integrated Environmental Assessment and Management, 15(1), 148-159. https://doi.org/10.1002/ieam.4101.

Meadows, D. (1998). Indicators and information for sustainable development (78 p). Hartland Four Corners, VT: The Sustainablity Institute.

National Ecosystem Services Partnership. (2016). Federal Resource Management and ecosystem services guidebook (2nd ed.). Durham: National Ecosystem Services Partnership, Duke University. https://nespguidebook.com.

National Research Council. (2005). Valuing ecosystem services: Toward better environmental decision-making. Washington, DC: National Academies Press.

Nicholson, W., \& Snyder, C. (2012). Microeconomic theory: Basic principles and extensions. Nelson Education.

Norman, L., Villarreal, M., Lara-Valencia, F., Yuan, Y., Nie, W., Wilson, S., Amaya, G., \& Sleeter, R. (2012). Mapping socio-environmentally vulnerable populations access and exposure to ecosystem services at the US-Mexico borderlands. Applied Geography, 34, 413-424. https:// doi.org/10.1016/j.apgeog.2012.01.006.

Ojo, C., Mulvaney, K., Mazzotta, M., \& Berry, W. (2018). A marketing plan for scientists: Building effective products and connecting with stakeholders in meaningful ways. Solutions, 9(2), 1.

Olander, L., Polasky, S., Kagan, J. S., Johnston, R. J., Wainger, L., Saah, D., Maguire, L., Boyd, J., \& Yoskowitz, D. (2017). So you want your research to be relevant? Building the bridge between ecosystem services research and practice. Ecosystem Services, 26, 170-182. https://doi.org/10. 1016/j.ecoser.2017.06.003.

Olander, L. P., Johnston, R. J., Tallis, H., Kagan, J., Maguire, L. A., Polasky, S., Urban, D., Boyd, J., Wainger, L., \& Palmer, M. (2018). Benefit relevant indicators: Ecosystem services measures that link ecological and social outcomes. Ecological Indicators, 85, 1262-1272. https://doi.org/ 10.1016/j.ecolind.2017.12.001.

Parsons, G. (2017). The travel cost model. In P. A. Champ, K. J. Boyle, \& T. C. Brown (Eds.), A primer on non-market valuation (2nd ed., pp. 187-234). Dordrecht: Springer.

Piet, G., Delacámara, G., Gómez, C. M., Lago, M., Rouillard, J., Martin, R., \& van Duinen, R. (2017). Making ecosystem-based management operational. Deliverable 8.1, European Union's Horizon 2020 Framework Programme for Research and Innovation grant agreement No. 642317.

Richardson, L., \& Loomis, J. (2009). The total economic value of threatened, endangered and rare species: An updated meta-analysis. Ecological Economics, 68, 1535-1548.

Ringold, P., Boyd, J., Landers, D., \& Weber, M. (2013). What data should we collect? A framework for identifying indicators of ecosystem contributions to human well-being. Front Ecol Environ, 11(2), 98-105. https://doi.org/10.1890/110156.

Russell, M. J., Rhodes, C., Sinha, R. K., Van Houtven, G., Warnell, G., \& Harwell, M. C. (2020). Ecosystem-based management and natural capital accounting. In T. O’Higgins, M. Lago, \& T. H. DeWitt (Eds.), Ecosystem-based management, ecosystem services and aquatic biodiversity: Theory, tools and applications (pp. 149-164). Amsterdam: Springer.

Schultz, E., Johnston, R., Segerson, K., \& Besedin, E. (2012). Integrating ecology and economics for restoration: Using ecological indicators in valuation of ecosystem services. Restoration Ecology, 20(3), 304-310. https://doi.org/10.1111/j.1526-100X.2011.00854.x.

Sharpe, L., Hernandez, C., \& Jackson, C. (2020). Prioritizing stakeholders, beneficiaries and environmental attributes: A tool for ecosystem-based management. In T. O'Higgins, M. Lago, \& T. H. DeWitt (Eds.), Ecosystem-based management, ecosystem services and aquatic biodiversity: Theory, tools and applications (pp. 189-212). Amsterdam: Springer. 
Spash, C. L., \& Vatn, A. (2006). Transferring environmental value estimates: Issues and alternatives. Ecological Economics, 60(2), 379-388. https://doi.org/10.1016/j.ecolecon.2006.06.010.

Tashier, A., \& Ringold, R. (2019). A critical review of available ecosystem services data according to the final ecosystem goods and services framework. Ecosphere, 10, 3. https://doi.org/10.1002/ ecs2.2665.

Thaler, T., Boteler, B., Dworak, T., Holen, S., \& Lago, M. (2014). Investigating the use of environmental benefits in the policy decision process: A qualitative study focusing on the EU water policy. Journal of Environmental Planning and Management, 57(10), 1515-1530.

Vajjhala, S., John, A., \& Evans, D. (2008). Determining the extent of market and extent of resource for stated preference survey design using mapping methods (43 p). Washington, DC: Resources for the Future.

Wainger, L., \& Mazzotta, M. (2011). Realizing the potential of ecosystem services: A framework for relating ecological changes to economic benefits. Environmental Management, 48, 710. https://doi.org/10.1007/s00267-011-9726-0.

Wainger, L., King, D., Salzman, J., \& Boyd, J. (2001). Wetland value indicators for scoring mitigation trades. Stanford Environment Law Journal, 20(2), 413-477.

Wainger, L., King, D., Mack, R., Price, E., \& Maslin, T. (2010). Can the concept of ecosystem services be practically applied to improve natural resource management decisions? Ecol Econ, 69, 978-987. https://doi.org/10.1016/j.ecolecon.2009.12.011.

Wainger, L., Helcoski, R., Farge, K., Espinola, B., \& Green, G. (2018). Evidence of a shared value for nature. Ecological Economy, 154, 107-116. https://doi.org/10.1016/j.ecolecon.2018.07.025.

Woznicki, S., Baynes, J., Panlasigui, S., Mehaffey, M., \& Neale, A. (2019). Development of a spatially complete floodplain map of the conterminous United States using random forest. Science of the Total Environment, 647, 942-953. Accessed from EnviroAtlas: ftp://newftp. epa.gov/epadatacommons/ORD/EnviroAtlas/Estimated_floodplain_CONUS.zip.

Yee, S., Bousquin, J., Bruins, R., Canfield, T., DeWitt, T., de Jesús Crespo, R., Dyson, B., Fulford, R., Harwell, M., Hoffman, J., \& Littles, C. (2017). Practical strategies for integrating final ecosystem goods and services into community decision-making. Washington, DC: US Environmental Protection Agency, Office of Research and Development.

Open Access This chapter is licensed under the terms of the Creative Commons Attribution 4.0 International License (http://creativecommons.org/licenses/by/4.0/), which permits use, sharing, adaptation, distribution and reproduction in any medium or format, as long as you give appropriate credit to the original author(s) and the source, provide a link to the Creative Commons licence and indicate if changes were made.

The images or other third party material in this chapter are included in the chapter's Creative Commons licence, unless indicated otherwise in a credit line to the material. If material is not included in the chapter's Creative Commons licence and your intended use is not permitted by statutory regulation or exceeds the permitted use, you will need to obtain permission directly from the copyright holder.

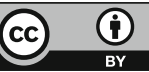

